\title{
Effect Size Statistics to Inform an Exploratory Analysis of a Double-Blinded, Randomised, Placebo Controlled Pilot Clinical Study to Evaluate the Efficacy of Naticol ${ }^{\circledR}$, Specific Fish Collagen Peptides to Alleviate Symptoms of Osteoarthritis in the Knee
}

\author{
Seán Lacey ${ }^{1 *}$, Christelle Bonnet ${ }^{2}$, Kelly Seamans ${ }^{3}$ and Andrea Doolan ${ }^{3}$ \\ ${ }^{1}$ Department of Mathematics, Cork Institute of Technology, Ireland \\ ${ }^{2}$ Weishardt International, France \\ ${ }^{3}$ Atlantia Food Clinical Trials, Cork, Ireland
}

Submission: June 06, 2019; Published: June 17, 2019

*Corresponding author: Seán Lacey, Department of Mathematics, Cork Institute of Technology, Bishops town, Cork, T12 P928, Ireland

Abstract

Background: Potential effects of different doses of specific fish collagen peptides ( $\mathrm{Naticol}^{\circledR}$ ) on the signs of skin ageing were firstly assessed in double-blind, randomised and placebo controlled clinical studies. The studies showed benefits of fish collagen peptides (Naticol ${ }^{\circledR}$ ) on skin firmness, skin hydration and wrinkle appearance. In addition to these benefits, some animal experiments have suggested that ingestion of specific fish collagen peptides $\left(\mathrm{Naticol}^{\circledR}\right)$ might also have beneficial effects on joint health such as osteoarthritis.

Aim: This pilot clinical trial study was designed to assess the safety and tolerability of daily oral doses of specific fish collagen peptides $\left(\mathrm{Naticol}^{\circledR}\right)$ in healthy subjects with knee osteoarthritis.

Methods: In a double-blinded, placebo controlled pilot clinical study, 30 adults (20 active; 10 placebo) consumed a $10 \mathrm{~g}$ sachet of the investigational product ( $\mathrm{Naticol}^{\circledR}$; specific fish collagen peptides) and a comparator product (maltodextrin) daily in 20cl of cold liquid (fruit juice, milk or cold tea) 15 minutes before breakfast, for 8 weeks. Potential pain reduction was tested using the Western Ontario McMaster Universities (WOMAC) scores; Quality of Life (QOL) using the Participant Global Assessment (SF-36v2 questionnaire) and Physical performance using the Short Physical Performance Battery (SPPB) at both baseline and after 8 weeks.

Results: From effect size statistics (Cohen's d), subjects in the active group experienced more of an improvement across the majority of measurements than subjects in the placebo group over the 8 weeks of the study. From the WOMAC Physical Function sub-score the placebo group experienced a small improvement $(d=0.68)$ against the active group's large improvement $(d=1.08)$. While for the WOMAC Composite score the active group experienced a large improvement $(\mathrm{d}=1.07)$. In terms of the SF-36v2 Social Functioning and Pain sub scores, there was no change in score for the placebo group $(d=0.00)$, while the active group noticed an improvement by small $(d=-0.34)$ and medium $(d=$ -0.50) amounts, respectively. While for the SF-36v2 Emotional Well-Being and General Healthy Issues sub scores, the placebo-based subjects dis-improved over the 8 weeks ( $d=0.07$ and 0.15 , respectively), while the subjects in the active group improved in both cases $(d=-0.18)$ and -0.09 , respectively). In terms of the SPPB, active group experienced an improvement in the Chair test and Total score. $(\mathrm{d}=0.47$ and $d=-0.33$, respectively). There was no difference in adverse events between groups ( $p>0.05$ ).

Conclusion: The results demonstrated that daily oral doses of specific fish collagen peptides $\left(\mathrm{Naticol}^{\circledR}\right)$ in healthy subjects with knee osteoarthritis has the potential to reduce pain, improve quality of life and lower body function. Further studies with a higher dosage of product for subjects with a body weight greater than $70 \mathrm{~kg}$ should be performed.

Keywords: Clinical study; Effect size; Fish collagen peptides; Naticol ${ }^{\circledR}$; Osteoarthritis

Abbreviations: AE: Adverse Event; ANOVA: Analysis of Variance; BMI: Body Mass Index; CH: Collagen Hydrolysates; GP: General Practitioner; OA: Osteoarthritis; QOL: Quality of Life; SAE: Serious Adverse Event; SD: Standard Deviation; SF-36v2: Short Form - 36 Version 2; SPPB: Short Physical Performance Battery; WOMAC: Western Ontario and McMaster Universities Osteoarthritis Index 


\section{Introduction}

Osteoarthritis (OA) results from an imbalance of anabolism and catabolism in the joint, which may be influenced by the biological and mechanical environment. Excessive forces in specific regions of the joint surfaces and alterations in tissue responses, leading to the development of osteoarthritis are also exacerbated with abnormal loading of the knee joint due to overweight or a joint disorder [1-3].

Today, the total cost of osteoarthritis has been estimated to be between $1 \%$ and $2.5 \%$ of the total gross domestic product in western countries [4]. In Europe, over 100 million people have arthritis, and in the United States, the direct costs of arthritis were $\$ 51.1$ billion in 2004 [5]. As the number of elderly people increases, osteoarthritis represents a major economic burden on the health care systems and is a serious threat to the quality of life within the populations. For instance, in the UK in 2010, there were 4.7 million doctor appointments due to knee osteoarthritis for patients over 45 years. It has been predicted that this number will increase to 6.7 million by 2051 [6].

This pilot study was designed to assess the tolerability and efficacy of oral doses of fish collagen peptides $\left(\mathrm{Naticol}^{\circledR}\right.$, $10 \mathrm{~g} /$ day) in volunteers with knee osteoarthritis. The collagen hydrolysates or peptides $\left(\mathrm{Naticol}^{\circledR}\right)$ which were the object of this efficacy study were products derived from fish hydrolysed collagen (gelatin) suitable for use in human food. Previous clinical studies aimed at assessing the effects of oral intakes of fish collagen peptides, $\mathrm{Naticol}^{\circledR}$, on skin firmness and hydration, and the decrease of wrinkles were conducted using different dosages (10g/day; 5g/day; 2,5g/day) [7,8]. The results from Duteil et al. [7] and Sibilla et al. [8] confirmed preclinical and clinical human trials investigating the effects of oral supplementation with collagen peptides that have indicated the possibility that dietary compounds can modulate skin function. For example, Matsuda et al. [9] reported that in pigs a 9-week oral ingestion of collagen hydrolysates $(\mathrm{CH})$ induced increased fibroblast density and enhanced formation of collagen fibrils in the dermis in a proteinspecific manner. Literature also indicates benefits of collagen hydrolysates in joints as they are absorbed, distributed to joint tissues and have analgesic and anti-inflammatory properties [10-14].

The aim of the study was to determine the effect of 8 weeks' supplementation of $\mathrm{Naticol}^{\circledR}$, Fish collagen peptides on change in WOMAC scores; Quality of Life, using the Participant Global Assessment (SF-36v2 questionnaire) and Physical performance using the Short Physical Performance Battery (SPPB), along with supporting the safety of the product by recording any reported adverse events.

\section{Participants and Methods}

\section{Participants}

Subjects underwent an initial phone screen and were asked questions regarding their age, general health and osteoarthritis diagnosis. Forty eligible subjects were scheduled for an initial visit. The pilot study involved 2 visits over an 8-week period. At the initial visit, subjects were included if they were: Aged 30 to 75 years (inclusive); Had documented diagnosis of primary osteoarthritis $(\mathrm{OA})$ of the target knee made at least 12 months prior to the visit; Had radiographic evidence of OA in the tibiofemoral compartment of the target knee with at least 1 definite osteophyte and a measurable joint space, as diagnosed by standard X-rays; Had a Kellgree-Lawrence grade 2-4. Potential female subjects were excluded if they were pregnant, lactating or wished to become pregnant during the study. Subjects were also excluded if they: Had viscosupplementation in any joint including the target knee or other joint within 6 months prior to the initial visit; Had concomitant inflammatory disease or other condition that affects the joints; Had taken any calcium supplements within the previous 4-weeks; Had a disease/illness that would preclude supplement ingestion and/or assessment of safety and the study objectives and/or had a known allergy to components of the test product; Had lost > 5\% of their total body weight in the last 3 months.

The site, investigator, protocol, informed consent form and other pertinent documents for this study were approved by the Cork Research Ethics Committee of the Cork Teaching Hospitals, Lancaster Hall, 6 Little Hanover Street, Cork. All subjects gave their written consent according to the Helsinki Declaration.

\section{Design and conduct of study}

Table 1: Naticol@ values expressed in percentage of each amino acid reported to all amino acids and corresponding nutritional information.

\begin{tabular}{|c|c|}
\hline Glycine & 20.9 \\
\hline Proline & 12.6 \\
\hline Glutamic Acid & 11.6 \\
\hline Hydroxyproline & 10.5 \\
\hline Arginine & 8.9 \\
\hline Alanine & 8.3 \\
\hline Aspartic Acid & 5.1 \\
\hline Lysine & 3.5 \\
\hline Serine & 3.5 \\
\hline Threonine & 2.7 \\
\hline Leucine & 2.6 \\
\hline Phenylalanine & 2.3 \\
\hline Valine & 2 \\
\hline Isoleucine & 1.5 \\
\hline Hydroxylysine & 1.5 \\
\hline Histidine & 1.3 \\
\hline Methionine & 0.8 \\
\hline Tyrosine & 0.4 \\
\hline Cysteine + Cystine & 0.03 \\
\hline Total & 100 \\
\hline
\end{tabular}




\begin{tabular}{|c|c|}
\hline & Typical Values per 100g \\
\hline Energy & $1593 \mathrm{~kJ}(381 \mathrm{kCal})$ \\
\hline Protein & $95 \mathrm{~g}$ \\
\hline Moisture & $4.7 \mathrm{~g}$ \\
\hline Carbohydrates (of which sugars) & $0 \mathrm{~g}(0 \mathrm{~g})$ \\
\hline Total fats (of which saturated fats) & $0 \mathrm{~g}(0 \mathrm{~g})$ \\
\hline Ash (of which sodium) & $0.3 \mathrm{~g}(0.1 \mathrm{~g})$ \\
\hline Dietary fibres & $0 \mathrm{~g}$ \\
\hline Vitamins & $0 \mathrm{~g}$ \\
\hline
\end{tabular}

The pilot study was a double-blind, randomised, placebocontrolled clinical study in which adults, male or female, between 30 and 75 years of age, with a diagnosis of primary osteoarthritis of the target knee were included. The study occurred between May 9, 2017 (first subject, first visit) and December 12, 2017 (last subject, last visit). Based on findings from Kumar et al. [15], 30 subjects were randomised into one of two groups. 10 subjects were randomly assigned to the placebo group, with 20 subjects to the active group - i.e., receiving the investigational product (Naticol ${ }^{\circledR}$, fish collagen peptides). The investigational product (NATICOL ${ }^{\circledR}$, fish collagen peptides) was manufactured and released under the responsibility of Weishardt and was provided to the Coordinator/Investigator in boxes containing single dose sachets. A $10 \mathrm{~g}$ sachet of the investigational products and the comparator product (maltodextrin) were to be consumed one daily intake in $20 \mathrm{cl}$ of cold liquid (fruit juice, milk or cold tea) 15 minutes before breakfast, for 8 weeks. The Naticol ${ }^{\circledR}$ reveals the presence of numerous amino acids including proline, hydroxyproline, glycine and arginine, see Table 1 . Nutritional value is also summarized in Table 1.

At baseline, subjects were provided with a box containing 8-weeks supply of the study product, along with an additional 4-day supply in case of loss. Subjects were instructed to one sachet each morning, with their breakfast, for the duration of the study. Subjects returned after 8 weeks. At each visit the vitals, anthropometric measurements, concomitant medication and any adverse events were recorded. Subjects completed the following questionnaires: Western Ontario and McMaster Universities Osteoarthritis Index Likert Scale (WOMAC) and participant global assessment short form 36 (SF-36v2). Subjects returned any unused study product and compliance was assessed and new study product administered. Subjects also underwent the Short Physical Performance Battery (SPPB) test at each visit. Subjects were instructed to follow their standard diet and exercise routine and not consume medications that could interfere with the assessment of the study product for the duration of the study. Any symptoms and changes in health status or medications were recorded.

\section{Statistical analysis}

Subjects were randomized by a computer-generated schedule to either the active or placebo groups (2:1). All statistical analyses were carried out using SPSS Version 24 for Windows. All tests were twosided and performed at the $5 \%$ level of significance. Cohen's d was used to determine the strength (standardised mean difference) of statistical results: No effect: $0 \leq \mathrm{d}<0.2$; Small effect: $0.2 \leq \mathrm{d}<0.5$; Medium effect 0.5 $\leq \mathrm{d}<0.8$; Large effect $\mathrm{d} \geq 0.8$ [16]. Categorical parameters were summarized by means of absolute numbers. Numerical data were summarized by means of standard statistics (i.e., number of available data, mean, standard deviation, minimum, maximum). The change in subject's measurements (WOMAC scores; SF$36 \mathrm{v} 2$; SPPB) between treatment groups from baseline to the end of treatment were analyzed using a repeated measures ANOVA (with the appropriate test of normality, homogeneity of variance and sphericity carried out initially). The overall incidence of treatment-related adverse events was compared across groups by Fisher's exact test and the chi squared test.

\section{Measurements}

Analysis of WOMAC scores, SF-36v2 and SPPB were based on [17-19], respectively. The higher scores on the WOMAC indicate worse pain, stiffness, and functional limitations [20]. The SF6 36 consists of eight scaled scores, which are the weighted sums of the questions in their section. The lower the score the more disability [18]. In relation to the SPPB test, higher scores indicate better lower body function [21]. The clinical team for the study assessed each subject's-reported adverse event (AE) and categorized it according to Intensity; Relationship to study; Action taken; Outcome; Serious Adverse Event (SAE).

\section{Results}

Exploratory analysis on the effect of 8 weeks' supplementation of specific fish collagen peptides (Naticol ${ }^{\circledR}$ ), on osteoarthritis measurements, for subjects that completed the study

With the exception of gender, there was no difference in subjects across treatment groups at baseline, see Table 2. One subject from each treatment group had treatment discontinued due to nausea (active group) and an allergic reaction to the product (placebo group), see Table 3. Hence, results on measurements are reported on subjects that completed the study - i.e., 9:19 Placebo: Active.

Table 2: Count of subject demographics, along mean \pm SD [Min, Max] of vital signs, anthropometric measurements at baseline.

\begin{tabular}{|c|c|c|c|}
\hline & Placebo & Active & p-value \\
\hline $\mathrm{n}$ & 10 & 20 & $<0.001^{*}$ \\
\hline Male:Female & $0: 10$ & $2: 18$ & 0.463 \\
\hline Age (years) & $62.3 \pm 6.31[51,73]$ & $60.4 \pm 6.98[39,72]$ & \\
\hline
\end{tabular}




\section{Juniper Online Journal of Case Studies}

\begin{tabular}{|c|c|c|c|}
\hline Temperature $\left({ }^{\circ} \mathrm{C}\right)$ & $36.3 \pm 0.47[35.5,37.0]$ & $36.4 \pm 0.29[36.0,37.0]$ & 0.24 \\
\hline Systolic BP $(\mathrm{mmHg})$ & $121.0 \pm 16.02[93,148]$ & $125.1 \pm 16.65[91,148]$ & 0.53 \\
\hline Distolic BP $(\mathrm{mmHg})$ & $73.9 \pm 10.11[63,88]$ & $78.9 \pm 10.32[61,95]$ & 0.218 \\
\hline Pulse $(\mathrm{bpm})$ & $68.3 \pm 13.01[44,86]$ & $65.4 \pm 6.92[53,79]$ & 0.522 \\
\hline Weight $(\mathrm{kg})$ & $69.8 \pm 10.71[54.7,85.5]$ & $75.5 \pm 12.50[51.1,100.0]$ & 0.224 \\
\hline Height $(\mathrm{m})$ & $1.6 \pm 0.03[1.6,1.7]$ & $1.6 \pm 0.10[1.5,1.8]$ & 0.296 \\
\hline BMI $\left(\mathrm{kg} / \mathrm{m}^{2}\right)$ & $26.9 \pm 4.26[21.9,34.3]$ & $28.4 \pm 4.93[20.0,37.2]$ & 0.44 \\
\hline
\end{tabular}

*Binomial-test conducted (Active group only).

Table 3: Classification of reported adverse events.

\begin{tabular}{|c|c|c|c|c|c|c|c|c|}
\hline Group & Subject ID & Description & Visit & Intensity & $\begin{array}{c}\text { Relationship } \\
\text { to Study }\end{array}$ & $\begin{array}{l}\text { Action } \\
\text { Taken }\end{array}$ & Outcome & SAE \\
\hline \multirow{5}{*}{ Active } & 076-002 & $\begin{array}{l}\text { Subject got nausea and feltill } \\
\text { after consuming the product }\end{array}$ & Baseline & Moderate & Probable & $\begin{array}{c}\text { Treatment } \\
\text { discontinued }\end{array}$ & Recovered & No \\
\hline & 076-007 & $\begin{array}{l}\text { Clinically significant blood } \\
\text { pressure }\end{array}$ & Baseline & Moderate & Unrelated & $\begin{array}{l}\text { Referred to } \\
\text { GP }\end{array}$ & Resolved; Recovering & No \\
\hline & 076-013 & Nausea, diarrhoea & Week 08 & Moderate & Unlikely & None & Recovered & No \\
\hline & 076-014 & Head-cold & Week 08 & Mild & Unrelated & None & Recovered & No \\
\hline & 076-029 & Chest infection & Week 08 & Moderate & Unlikely & None & Recovered & No \\
\hline \multirow{4}{*}{ Placebo } & 076-009 & $\begin{array}{l}\text { slipped and fell at home, } \\
\text { bruised side and thigh }\end{array}$ & Week 08 & Moderate & Unrelated & None & Resolved; Recovering & No \\
\hline & 076-020 & $\begin{array}{l}\text { Allergic reaction to the product. } \\
\text { rash on skin red and blistered }\end{array}$ & Baseline & Moderate & Probable & $\begin{array}{c}\text { Treatment } \\
\text { discontinued }\end{array}$ & $\begin{array}{l}\text { Resolving; Not } \\
\text { recovered }\end{array}$ & No \\
\hline & 076-030 & Mild Head-cold \& Dry Cough & Week 08 & Mild & Unlikely & None & Resolved; Recovering & No \\
\hline & 076-033 & $\begin{array}{l}\text { Bruised ribs, chin, nose and } \\
\text { wrist after a fall. }\end{array}$ & Week 08 & Moderate & Unrelated & None & Resolved; Recovering & No \\
\hline \multicolumn{3}{|r|}{ p-value } & $1.000^{*}$ & $1.000^{*}$ & $0.894^{* *}$ & $0.638^{* *}$ & $0.051^{* *}$ & $\mathrm{~N} / \mathrm{E}$ \\
\hline
\end{tabular}

* Fisher's exact test; ** Chi-squared test.

Upon investigation it was apparent that subjects in the active group experienced more of an improvement across the majority of measurements than subjects in the placebo group over the 8 weeks of the study, see Table 4, Table 5 \& Figure 1 . The magnitude of the differences observed were compared using effect size i.e., the standardized mean difference in measurements from

baseline to 8 weeks, with a larger difference, in magnitude of the effect size statistics, found in the active group than the placebo group across the majority of measurements. Due to the exploratory nature of the study and the small sample size, comparing effect sizes are a reliable approach to inform the statistical power of future studies, [22].

Table 4: Effect of 8 weeks' supplementation of Naticol 8 , on osteoarthritis related measurements, for subjects that completed the study.

\begin{tabular}{|c|c|c|c|c|c|}
\hline \multirow{2}{*}{} & \multicolumn{2}{|c|}{ Placebo (n= 9) } & \multicolumn{2}{|c|}{ Active (n= 19) } \\
\cline { 2 - 5 } & Baseline* & Week 08 & Baseline* & Week 08 & p-value \\
\hline WOMAC Pain sub-scores & $6.9 \pm 3.55$ & $4.8 \pm 5.04$ & $7.1 \pm 3.05$ & $4.3 \pm 2.98$ & 0.583 \\
\hline WOMAC Physical Function sub-scores & $25.8 \pm 10.72$ & $18.4 \pm 15.15$ & $28.6 \pm 10.34$ & $19.3 \pm 10.30$ & 0.606 \\
\hline WOMAC Composite score during the study & $36.3 \pm 15.53$ & $25.8 \pm 21.06$ & $38.9 \pm 13.55$ & $26.6 \pm 13.61$ & 0.726 \\
\hline SF-36v2 Role Limitations due to Physical Problems & $56.3 \pm 23.59$ & $70.1 \pm 22.273$ & $58.9 \pm 16.05$ & $71.1 \pm 20.75$ & 0.867 \\
\hline SF-36v2 Role Limitations due to Emotional Problems & $69.4 \pm 22.44$ & $80.6 \pm 17.18$ & $73.7 \pm 21.91$ & $78.3 \pm 21.72$ & 0.548 \\
\hline SF-36v2 Emotional Well-Being score & $70.2 \pm 10.97$ & $69.3 \pm 23.75$ & $69.9 \pm 11.11$ & $71.4 \pm 12.09$ & 0.564 \\
\hline SF-36v2 Social Functioning scores & $76.4 \pm 26.84$ & $76.4 \pm 23.75$ & $68.4 \pm 26.80$ & $77.6 \pm 23.78$ & 0.392 \\
\hline SF-36v2 Pain score & $56.7 \pm 23.08$ & $56.7 \pm 31.62$ & $51.6 \pm 16.33$ & $61.4 \pm 22.57$ & 0.272 \\
\hline SF-36v2 General Health score & $72.2 \pm 22.65$ & $70 \pm 18.03$ & $70.8 \pm 16.44$ & $71.8 \pm 14.83$ & 0.541 \\
\hline SPPB Balance Score & $4.0 \pm 0.00$ & $4.0 \pm 0.00$ & $4.0 \pm 0.00$ & $4.0 \pm 0.00$ & \\
\hline SPPB Chair Test Score & $1.9 \pm 1.17$ & $2.2 \pm 1.20$ & $2.1 \pm 1.09$ & $2.5 \pm 1.01$ & 0.769 \\
\hline SPPB Total score & $10 \pm 1.20$ & $10.1 \pm 1.25$ & $10.1 \pm 1.09$ & $10.4 \pm 1.18$ & 0.639 \\
\hline
\end{tabular}

*No difference between groups at baseline. 


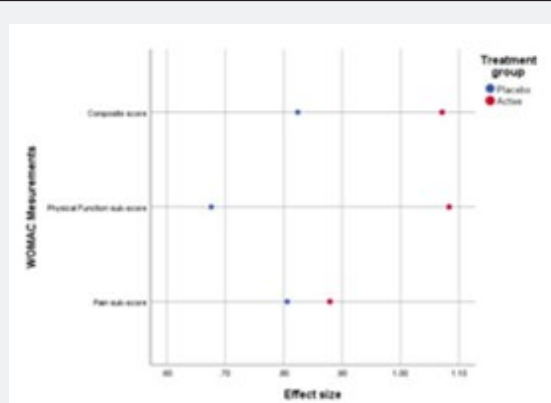

(a)

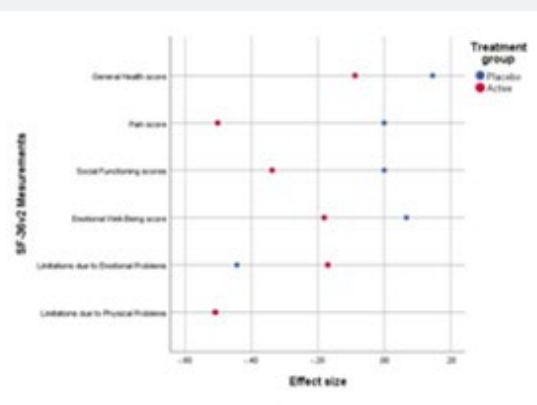

(b)

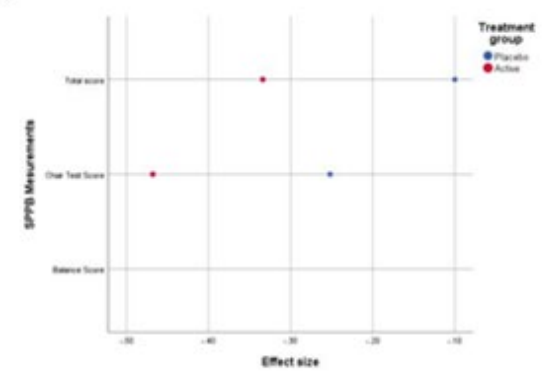

(c)

Figure 1: Effect size calculations on osteoarthritis related measurements from Baseline - Week 8 for (a) WOMAC scores;

(b) SF-36v2;

(c) SPPB.

Table 5: Cohen's d, within groups effect size calculations on osteoarthritis related measurements from baseline to Week 08 .

\begin{tabular}{|c|c|c|}
\hline Measurements & Placebo & Active \\
\hline WOMAC Pain sub-scores & 0.81 & 0.88 \\
\hline WOMAC Physical Function sub-scores & 0.68 & 1.08 \\
\hline WOMAC Composite score during the study & 0.82 & 1.07 \\
\hline SF-36v2 Role Limitations due to Physical Problems & -0.51 & -0.51 \\
\hline SF-36v2 Role Limitations due to Emotional Problems & -0.44 & -0.17 \\
\hline SF-36v2 & 0.07 & -0.18 \\
\hline SF-36v2 & 0 & -0.34 \\
\hline SF-36v2 & 0 & -0.5 \\
\hline SF-36v2 & 0.15 & -0.09 \\
\hline SPPB Balance Score & 0 & 0 \\
\hline SPPB Chair Test Score & -0.25 & -0.47 \\
\hline SPPB Total score & -0.1 & -0.33 \\
\hline
\end{tabular}

\section{WOMAC}

Noting a higher score on the WOMAC indicates worse pain, stiffness, and functional limitations [20]. Hence, a positive effect size (Baseline - Week 8) represents an improvement in WOMAC over the 8 weeks. From Table 5 \& Figure 1(a), with the WOMAC Pain sub-score, both groups experienced a large improvement, $\mathrm{d}=0.81,0.88$, respectively [16]. For WOMAC Physical Function the placebo group experienced a small improvement $(d=0.68)$ against the active group's large improvement $(\mathrm{d}=1.08)$. Finally, for the WOMAC Composite score the placebo group experienced a medium improvement $(\mathrm{d}=0.82$ ) against the active groups even larger improvement $(d=1.07)$. The WOMAC stiffness sub score is not presented Table 5 and Figure 1(a).

\section{SF-36v2}

Noting the lower the score the more disability [18]. Hence, a negative effect size (Baseline - Week 8) represents less disability (an improvement) over the 8 weeks. In terms of Role Limitations due to Physical Problems score, Role Limitations due to Emotional Problems score active group experienced medium improvements, see Table 5. Physical functioning, energy and vitality scores are not presented in Table 5 and Figure 1(b). With regard Social Functioning and Pain scores, there was no change in score for the placebo group $(d=0.00)$, while the active group noticed an improvement by a small $(\mathrm{d}=-0.34)$ and medium $(\mathrm{d}$ $=-0.50$ ) amount, respectively. Finally, for Emotional Well-Being and General Healthy Issues the placebo-based subjects dis- 
improved over the 8 weeks ( $d=0.07$ and 0.15 , respectively), while the subjects in the active group improved in both cases $(\mathrm{d}$ $=-0.18$ ) and 0.09, respectively).

\section{SPPB}

Noting higher scores indicate better lower body function [21]. Hence, a negative effect size (Baseline - Week 8) represents an improvement in lower body function over the 8 weeks. Both groups experienced an improvement in the Chair test and Total score. While the placebo group experienced a small and negligible improvements ( $d=-0.25$ and -0.10 , respectively), while the active group experienced a small improvement in both tests $(\mathrm{d}=-0.47$ and $\mathrm{d}=-0.33$, respectively). Gait score results are not presented in Table 5 and Figure 1(c).

\section{Adverse events}

Fisher's exact test found there was a statistically insignificant association between the number of adverse events reported per visit and treatment group $(\mathrm{p}=1.000)$, see Table 3. Furthermore, there was a statistically insignificant association between treatment group and the: Intensity, Relationship to study; Action taken and Outcome of an adverse event ( $\mathrm{p}=1.000,0.894,0.638$ and 0.051 , respectively).

\section{Discussion}

This double-blinded, placebo-controlled pilot clinical study demonstrates the potential for once daily oral doses of Naticol ${ }^{\text {, }}$ specific fish collagen peptides, Naticol ${ }^{\circledR}$, to alleviate symptoms of osteoarthritis in the knee. The study design was exploratory in nature, and effect size calculations show that subjects in the active group experienced more of an improvement across the majority of measurements than subjects in the placebo group over the 8 weeks of the study. These results corroborate those of previous preclinical and clinical studies to assess the potential effects of collagen hydrolysates on joint pain and physical mobility as assessed by the Western Ontario McMaster Universities (WOMAC) scoring system.

Clinical studies suggest that the ingestion of $10 \mathrm{~g}$ collagen hydrolysates daily reduces pain in patients with osteoarthritis of the knee or hip while blood concentration of hydroxyproline is increased. Clinical use was associated with minimal adverse effects, mainly gastrointestinal, characterized by fullness or unpleasant taste [23].

In a prospective, randomized, double-blind, placebocontrolled study in elderly women with mild-to moderate knee osteoarthritis, oral intake of collagen peptides for a duration of 6 months showed to significantly reduce joint pain and improve physical mobility as assessed by the Western Ontario McMaster Universities (WOMAC) scoring system. This clinical study confirmed that collagen peptides are a highly efficient nutraceutical to improve joint health in patients with osteoarthritis which can help to maintain an active lifestyle throughout ageing [24].
We can also indicate a double-blind, placebo-controlled, randomized trial with collagen hydrolysates isolated from pork skin (PCP) and bovine bone (BCP) sources carried out to study the effectiveness of orally supplemented collagen peptide to control the progression of osteoarthritis in patients diagnosed with knee osteoarthritis. Improvement in treatment with reduction in WOMAC and quality of life (QOL) scores from baseline to 13 weeks were recorded. Indeed, all the score levels of WOMAC and QOL decreased significantly $(\mathrm{p}<0.01)$ in the study group compared to placebo group after week 13. Safety and tolerability were also good [15].

Additionally, research in mice has demonstrated that after oral administration of radiolabeled gelatin hydrolysate, the radioactivity was specifically found in cartilage indicating an accumulation of these peptides within the connective tissue [25]. The study demonstrated the intestinal absorption and cartilage accumulation of collagen peptide. Thus, the potential role of collagen hydrolysates in repair of damaged cartilage could be associated with the accumulation of orally administered collagen hydrolysates. A recent animal study has also suggested that oral ingestion of collagen hydrolysates 9 might have beneficial effects on joint health such as osteoarthritis (OA) as collagen hydrolysates might reduce the morphological changes associated with osteoarthritic cartilage destruction in knee joints, [26].

This mechanism about absorption, distribution and collagen peptide accumulation in cartilage may explain the benefits we clinically recorded on joint pain and physical mobility. However, anti-inflammatory properties may also be an additional way for benefits. Indeed, the literature reports that intra-articular administration of collagen in the knee of subjects with osteoarthritis demonstrated a significant local inflammation decrease (increase in T regs, IL-10 and decrease in IL-1 $\beta$ ) and a mitigation in the symptoms inherent to the pathology [13]. Similarly, oral administration of collagen hydrolysates in mice with post-traumatic osteoarthritis inhibited synovial inflammation and induced cartilage regeneration [12].

Moreover, in this pilot clinical trial study, we may indicate that from the 28 (9:19 Placebo: Active) subjects that completed the study, 5 (55.6\%) of the placebo group and $14(73.7 \%)$ of the active group had a body weight greater than $70 \mathrm{~kg}$ at baseline. From Table 2, the maximum weight of subjects (that completed the study) at baseline was $85.5 \mathrm{~kg}$ and $100.0 \mathrm{~kg}$ for the placebo and active groups, respectively. In Shigemura et al. [27], the daily ingested dose of collagen hydrolysates is linked to the body weight. These authors examined the relationship between ingested dose/kg body weight and food-derived hydroxyproline levels in human plasma to estimate the effective beneficial dose of the collagen peptides. Hence, healthy volunteers ingested 30.8, 153.8 and $384.6 \mathrm{mg}$ per $\mathrm{kg}$ body weight of collagen hydrolysates. The average plasma concentration of hydroxyproline containing peptides was dose-dependent, reaching maximum levels of 6.43, 
20.17 and $32.84 \mathrm{nmol} / \mathrm{ml}$ following ingestion of 30.8, 153.8 and $384.6 \mathrm{mg}$ doses of collagen hydrolysate, respectively. Ingesting over $153.8 \mathrm{mg}$ of collagen hydrolysate significantly increased the average concentrations of the free and peptide forms of hydroxyproline in plasma. The hydroxyproline absorption limit was not reached with ingestion of as much as $384.6 \mathrm{mg}$ of collagen hydrolysate per kg body weight. These finding suggest that ingestion of less than $30.8 \mathrm{mg}$ of collagen hydrolysate per body weight is not effective for health benefits. They also show that the dose is calculated taking account of body weight.

Hence, doses may vary from one subject to another due to the variations of body weight. In this way, in order to maintain a similar dose per kg body weight between all subjects, the $100 \mathrm{~kg}$ subjects who received a daily dose of $10 \mathrm{~g}$ of specific fish collagen peptides $\left(\mathrm{Naticol}^{\circledR}\right)$ should have received more than $10 \mathrm{~g} /$ day compared to the ones who received $10 \mathrm{~g} /$ day for a body weight equivalent to $70 \mathrm{~kg}$. Here, the dose of collagen hydrolysates per body weight was not equivalent between all subjects due to the huge body weight

variations. However, all subjects received the minimum dose of collagen hydrolysates reported by Shigemura et al. [27] for benefits. This dose of collagen hydrolysates ingested by the subjects with a very high body weight was nevertheless enough to demonstrate significant benefits and larger benefits in the active group.

\section{Conclusion}

This pilot clinical trial study, which consisted in a once daily treatment for 8 consecutive weeks, indicates that oral supplement specific fish collagen peptides have some interesting effects on knee osteoarthritis symptoms. The results demonstrated that daily oral doses of specific fish collagen peptides $\left(\mathrm{Naticol}^{\circledR}\right)$ in healthy subjects with knee osteoarthritis has the potential to reduce pain, improve quality of life and lower body function. Further studies with an extension of duration to 12 weeks or more and a higher dosage of product for subjects with a body weight greater than $70 \mathrm{~kg}$ should be performed to confirm these preliminary results.

\section{Acknowledgments}

The study was funded by Weishardt International Group (France) which provided the fish collagen peptides $\left(\mathrm{Naticol}^{\circledR}\right.$ ) assessed in this study.

\section{References}

1. Buckwalter JA, Martin J (1995) Degenerative joint disease. Clin Symp $47(2): 1-32$.

2. Cooper C (2000) Risk factors for the incidence and progression of radiographic knee osteoarthritis. Arthritis Rheum 43(5): 995-1000.

3. Zhou ZY, Liu YK, Chen HL, Liu F (2014) Body mass index and knee osteoarthritis risk: a dose response meta-analysis. Obesity (Silver Spring) 22(10): 2180-2185.

4. March LM, Bachmeier CJ (1997) Economics of osteoarthritis: a global perspective. Baillieres Clin Rheumatol 11(4): 817-834.
5. Arthritis Care (2006) The impact of arthritis (statistics). Arthritis Care, UK.

6. Arthritis Research UK (2013) Osteoarthritis in general practise. Arthritis Research UK.

7. Duteil L, Queille-Roussel C, Maubert Y, Esdaile J, Bruno-Bonnet C, et al. (2016) Specific natural bioactive type 1 collagen peptides oral intake reverse skin aging signs in mature women. Journal of Aging Research \& Clinical Practice 5(2).

8. Sara S, Martin G, Sarah B, Raja AB, Genovese L (2015) An Overview of the Beneficial Effects of Hydrolysed Collagen as a Nutraceutical on Skin Properties: Scientific Background and Clinical Studies. The Open Nutraceuticals Journal 8: 29-42.

9. Matsuda N, Koyama Y, Hosaka Y (2006) Effects of ingestion of collagen peptide on collagen fibrils and glycosaminoglycans in the dermis. J Nutr Sci Vitaminol (Tokyo) 52(3): 211-215.

10. Bruyère 0 , Zegels B, Leonori L, Rabenda V. Janssen A, et al. (2012) Effect of collagen hydrolysate in articular pain: a 6-month randomized, double-blind, placebo controlled study. Complement Ther Med 20(3): 124-130.

11. Clark KL, Sebastianelli W, Flechsenhar KR, Aukermann DF, Meza F, et al. (2000) 24-Week study on the use of collagen hydrolysate as a dietary supplement in athletes with activity-related joint pain. Curr Med Res Opin 24(5): 1485-1496.

12. Dar QA, Maynard RD, Liu Z, Schott EM, Catheline S, et al. (2016) Oral hydrolyzed type 1 collagen induces chondroregeneration and inhibits synovial inflammation in murine posttraumatic osteoarthritis. Osteoarthritis Cartilage 24(Supp 1): S532-S533.

13. Furuzawa-Carballeda J, Lima G, Llorente L, Nuñez-Álvarez C, RuizOrdaz BH, et al. (2012) Polymerized-type I collagen downregulates inflammation and improves clinical outcomes in patients with symptomatic knee osteoarthritis following arthroscopic lavage: a randomized, double-blind, and placebo-controlled clinical trial. ScientificWorldJournal 2012: 342854.

14. Hartog A, Cozijnsen M, de Vrij G, Garssen J (2013) Collagen hydrolysate inhibits zymosan induced inflammation. Exp Biol Med (Maywood) 238(7): 798-802.

15. Kumar S, Sugihara F, Suzuki K, Inoue N, Venkateswarathirukumara S (2015) A double-blind, placebo-controlled, randomised, clinical study on the effectiveness of collagen peptide on osteoarthritis. J Sci Food Agric 95(4): 702-707.

16. Cohen J. Statistical Power Analysis for the Behaviorial Sciences Routledge ISBN 1-134-74270.

17. McConnell S, Kolopack P, Davis AM (2001) The Western Ontario and McMaster Universities Osteoarthritis Index (WOMAC): a review of its utility and measurement properties. Arthritis Rheum 45(5): 453-461.

18. Jenkinson C, Stewart-Brown S, Petersen S, Paice C (1999) Assessment of the SF-36 version 2 in the United Kingdom. J Epidemiol Community Health 53(1): 46-50.

19. Gómez JF, Curcio CL, Alvarado B, Zunzunegui MV, Guralnik J (2013) Validity and reliability of the Short Physical Performance Battery (SPPB) Colomb Med (Cali) 44(3): 165-171.

20. American College of Rheumatology. Western Ontario and McMaster Universities Osteoarthritis Index (WOMAC).

21. Guralnik JM, Simonsick EM, Ferrucci L, Glynn RJ, Berkman LF, et al. (1994) A short physical performance battery assessing lower extremity function: Association with self-reported disability and prediction of mortality and nursing home admission. Journal of Gerontology 49(2): M85-M94.

22. Sullivan GM, Feinn R (2012) Using Effect Size-or Why the P Value Is Not Enough. J Grad Med Educ 4(3): 279-282. 
23. Moskowitz RW (2000) Role of collagen hydrolysate in bone and joint disease. Semin Arthritis Rheum 30(2): 87-99.

24. Jiang JX, YU S, Huang QR, Zhang XL, Zhang CQ et al. (2014) Collagen peptides improve knee osteoarthritis in elderly women A 6-month randomized, double-blind, placebo-controlled study. Agro Food Industry Hi Tech Vol 25(2).

25. Oesser S, Adam M, Babel W, Seifert J (1999) Oral administration of $14 \mathrm{C}$ labelled gelatin hydrolysate leads to an accumulation of radioactivity in cartilage of mice (C57/BL). J Nutrient Metabolism 129(10): 18911895.
26. O’Hara H, Ilda H, Ito K, Takeuchi Y, Nomura Y (2010) Effect of Pro-Hyp, a collagen hydrolysate derived peptide, on hyaluronic acid synthesis using in vitro cultured synovium cells and oral ingestion of collagen hydrolysate in a guinea pig model of osteoarthritis. Biosci Biotechnol Biochem 74: 2096-2099.

27. Shigemura Y., Kubomura D, Sato Y (2014) Dose-dependent changes in the levels of free and peptide forms of hydroxyproline in human plasma after collagen hydrolysate ingestion. Food Chem 159: 328-332.

\section{Your next submission with Juniper Publishers will reach you the below assets}

- Quality Editorial service

- Swift Peer Review

- Reprints availability

- E-prints Service

- Manuscript Podcast for convenient understanding

- Global attainment for your research

- Manuscript accessibility in different formats

( Pdf, E-pub, Full Text, Audio)

- Unceasing customer service

Track the below URL for one-step submission https://juniperpublishers.com/online-submission.php 